\title{
Kinetic Study on Catalytic Cracking of Rubber Seed (Hevea brasiliensis) Oil to Liquid Fuels
}

\author{
Wara Dyah Pita Rengga ${ }^{1 *}$, Prima Astuti Handayani ${ }^{1}$, Sri Kadarwati², \\ Agung Feinnudin ${ }^{3}$ \\ ${ }^{1}$ Department of Chemical Engineering, Universitas Negeri Semarang, Kampus Sekaran \\ Gunungpati, Semarang 50229, Indonesia \\ 2 Department of Chemical, Universitas Negeri Semarang, Kampus Sekaran Gunungpati, \\ Semarang 50229, Indonesia \\ ${ }^{3}$ Education and Training Agency, Ministry of Energy and Mineral Resources of Republic \\ Indonesia, Jl Poncol Raya No. 39 Ciracas, Jakarta 13740, Indonesia
}

Received: 3rd December 2013; Revised: 5th December 2014; Accepted: 7th December 2014

\section{Abstract}

Reaction kinetics of catalytic cracking of rubber seed oil to liquid fuels has been investigated. The reaction was performed with sulfuric acid as catalyst at temperatures of $350-450{ }^{\circ} \mathrm{C}$ and the ratio of oilcatalyst of 0-2 wt.\% for 30-90 minutes. Kinetics was studied using the model of 6-lump parameters. The parameters were rubber seed oil, gasoline, kerosene, diesel, gas, and coke. Analysis of experimental data using regression models to obtain reaction rate constants. Activation energies and preexponential factors were then calculated based on the Arrhenius equation. The simulation result illustrated that the six-lump kinetic model can well predict the product yields of rubber seed oil catalytic cracking. The product has high selectivity for gasoline fraction as liquid fuel and the smallest amount of coke. The constant indicates that secondary reactions occurred in diesel products compared to gasoline and kerosene. The predicted results indicate that catalytic cracking of rubber seed oil had better be conducted at $450{ }^{\circ} \mathrm{C}$ for 90 minutes using 0.5 wt.\% catalyst. (C) 2015 BCREC UNDIP. All rights reserved.

Keywords: Catalytic Cracking; Kinetics; Rubber Seed Oil; Liquid Fuel; six-lump

How to Cite: Rengga, W.D.P., Handayani, P.A., Kadarwati, S., Feinnudin, A. (2015). Kinetic Study on Catalytic Cracking of Rubber Seed (Hevea brasiliensis) Oil to Liquid Fuels. Bulletin of Chemical Reaction Engineering \& Catalysis, 10 (1): 50-60. (doi:10.9767/bcrec.10.1.5852.50-60)

Permalink/DOI: http://dx.doi.org/10.9767/bcrec.10.1.5852.50-60

\section{Introduction}

In the future, demand for bio-fuels will rise due to the rise in the price of fossil fuel, energy security reasons and environmental issues. A growing trend towards employing modern tech-

\section{* Corresponding Author}

E-mail: wdpitar@email.unnes.ac.id; pita.rengga@gmail.com (W.D.P. Rengga) Tel: +62-24-8508101, Fax: +62-24-8508101 nologies and efficient bio fuels conversion are becoming cost-wise competitive fossil fuels in developed countries [1]. Renewable energy technologies use the seed oils of plant to produce an attractive alternative fuel. Liquid fuels are primarily used to fuel transportation vehicle and applicable to fuel engines or fuel cells for electricity generation [2]. The seed oils are converted into liquid fuels due to their high energy density, liquid nature and availability as a non-edible renewable feedstock such as 
rubber seed oil (RSO).

The rubber seed production potential in Indonesia is about $120 \mathrm{~kg} / \mathrm{ha}$ per annum. The productivity of RSO per hectare per annum is reported as $170 \mathrm{~kg}$ oil/ha. The estimated availability of rubber seed is about $280 \mathrm{~kg}$ seed/ha/year from 3 million hectare of rubber plantation. At present, RSO has found as natural production of seeds remain under utilized and any major application such as biodiesel (methyl ester) [3-4] and alkyl resins [5]. In to order obtained diversifying product from RSO it is necessary to introduced and upgraded the process through catalytic cracking process.

Numerous catalytic cracking reactions have been used to convert palm oil [6-8], jatropha oil [9], cottonseed oil [10] into liquid fuels. The composition of palm oils, vegetable oils and cottonseed oils are different with RSO, mainly unsaturated fatty acid. The advantage of rubberseed is the content of unsaturated fatty acids are higher than these oils around 80-85\%. However, RSO as possible can be done to application of catalytic cracking process. A primary cracking is characterized by the formation of a fatty acid through the decomposition of triglyceride molecules which occurs through breakage of the ester bonds. The secondary cracking is characterized by the degradation of the acids produced in the first stage leading to the formation of hydrocarbons with properties similar to those of petroleum products.

Catalytic cracking process using a newly developed catalyst has enabled to produce high quality. The general catalysts which have been use to cracking process is solid catalyst such silica sand [10] and zeolite[6,7,9,11]. However the used of solid heterogeneous catalyst may produce coke which caused fouling in catalyst pores and lead to deactivation of catalyst. The liquid homogenous can covered the obstacle that can performed in the used of solid heterogeneous catalyst. The phase is similar to the raw material which favorable to the process of interface contact between catalyst and the oils. It is make homogenous catalyst intrinsically more active and selective compared to heterogeneous catalyst [12].

It is necessary to conduct a research on RSO catalytic cracking using sulfuric acid as homogenous catalyst to find out the potency of RSO producing liquid fuel. After reaction, sulfuric acid removal is necessarily conducted from the product by washing in water. The sulfuric acid is highly soluble in water. Some water needed until the mixture has a $\mathrm{pH}$ of 7 . Water settles to the bottom and then siphon off the liquid fuels (gasoline, kerosene, and diesel).
However the research is only studying kinetic of catalytic cracking reaction of RSO to liquid fuels.

The study of kinetic reaction needs to be done to find out the kinetic parameter such as activation energy and pre-exponential factor. The most importance aspects of catalytic cracking process are kinetic study. It should be done to model and simulate the reactor, predicted the distribution of many products, designed the process, and optimized the operational conditions for industrial application. The several kinetic models for catalytic cracking for production of liquid fuel were used feedstock from naphta [13], palm oil [14] mixture of palm oil and fatty-acid's palm oil [15] and gas oil [16]. RSO can be converted into liquid fuels through complex reactions those occur during the oil cracking which aims to break large molecules into smaller ones such as gasoline, kerosene, and diesel fraction, gas fraction, and coke.

The objective of the present investigation is to design a suitable kinetic model for RSO cracking using sulfuric acid catalyst for the production of liquid fuels (hydrocarbon). The reaction parameters of the proposed kinetic model are evaluated and experimental data obtained are compared with the calculated values obtained from proposed model. Kinetic parameters were then estimated based on the regression method. After the estimation of the kinetic parameters, the variations of product yields were predicted using operating conditions.

\section{Materials and Methods}

\subsection{Preparation of Rubber Seed Oils}

Rubber seed (Hevea brasiliensis) originated from Perhutani PTP Nusantara IX Semarang, Indonesia, was composed predominantly of linoleic acid, which was C18:2 unsaturated fatty acid. RSO contains about $80 \%$ unsaturated fatty acids. Properties of RSO compared with the other rubber seed were given in Table 1. The raw rubber-seed oil was degummed using phosphoric acid 1\% wt. oils. RSO was used for cracking study in the present investigation.

\subsection{Catalytic Cracking Method}

RSO was fed in stainless steel reactor (110 $\mathrm{mm}$ height x $10 \mathrm{~mm}$ ID) (Figure 1). The reactor was used in catalytic cracking processes and equipped with a furnace and a thermocouple. A certain amount of sulfuric acid was used as the catalyst in catalytic cracking processes which was obtained from Merck. Reaction was performed at various temperatures which heated 
externally at rate of $10{ }^{\circ} \mathrm{C} / \mathrm{min}$. Once the temperature was reached subsequently, the catalyst was introduced into the reactor by injection through a sample input hole. The catalyst $1.0 \%$ wt. was fed by liquid syringe-metering pump to add into RSO. The catalytic cracking process was done at different reaction times. The ranges of operating conditions for catalytic cracking of rubber seed are given in Table 2. The product gases were allowed to pass through a spiral condenser with flow of ice water. The weight of the gaseous products was estimated by weight of RSO be subtracted by weight of the residual oil, the liquid product, and the coke formed. The coke formed was separated by decanting the liquid products. The liquid products analyzed using GC-MS were

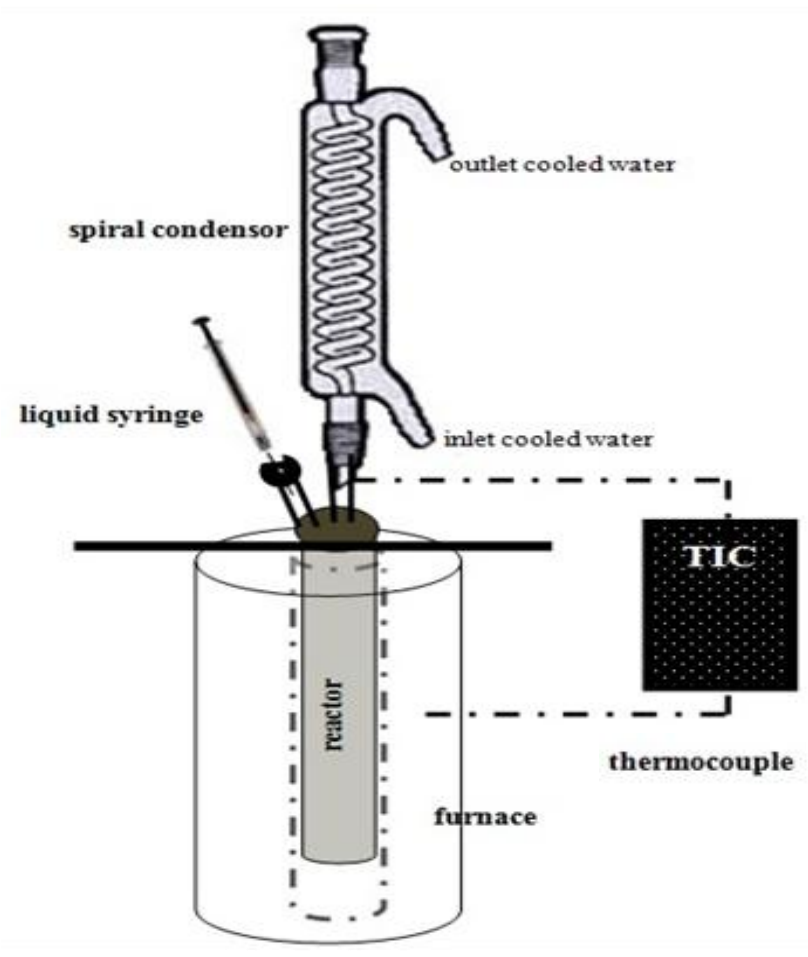

Figure 1. Catalytic cracking reactor used for identifying the compounds in the liquid products. GC-MS with accuracy levels of 1/100 for liquid (gasoline, kerosene, and diesel) identification.

\subsection{Product Analysis}

The weight of residue which was not converted or phase that was not distilled is residual oil. Yield (Xp) in wt.\% after the reaction is the weight of RSO subtracted by weight of residual oil (RO). These results compared with the weight of initial RSO are shown in Equation (1). The data of final volume measurement from obtained volume is shown in Table 3.

$$
X p(w t . \%)=\frac{R S O(g)-R O(g)}{R S O(g)} x 100 \%
$$

Conversion of RSO with the addition of sulfuric acid catalyst into gaseous organics, liquid products (LP) and solid coke products was expressed respectively in units of wt.\%. Product concentration (wt.\%) for liquid products divided into gasoline, kerosene and diesel is shown in Equation (2).

$$
L P(w t . \%)=\frac{\text { mass of product }(g)}{\text { RSO feedstock }(g)} \times 100 \%
$$

Table 2. Operating conditions for catalytic cracking

\begin{tabular}{lc}
\hline \multicolumn{1}{c}{ Parameter } & Value \\
\hline Reaction temperature $\left({ }^{\circ} \mathrm{C}\right)$ & $350-450$ \\
Reaction time (minute) & $30-90$ \\
Catalyst weight (wt.\%) & $0.0-2.0$
\end{tabular}

Table 1. Properties of Rubber Seed Oil

\begin{tabular}{ccccc}
\hline \multirow{2}{*}{ Property } & \multicolumn{4}{c}{ Rubber Seed Oil } \\
\cline { 2 - 5 } & {$[\mathbf{3}]$} & {$[\mathbf{1 1 ]}$} & {$[\mathbf{1 7 ]}$} & This research \\
\hline Fatty acid composition (\%) & & & & \\
- Palmitic acid (C16:0) & 10.2 & 8.8 & 8.8 & 10.4 \\
- Stearic Acid (C18:0) & 8.7 & 7.7 & 6.2 & 8.3 \\
- Oleic Acid (C18:1) & 24.6 & 24 & 39.0 & 24.8 \\
- Linoleic acid (C18:2) & 39.6 & 36.1 & 42.1 & 40.0 \\
- Linolenic acid (C18:3) & 16.3 & 20.2 & 2.4 & 16.5 \\
& & & & \\
Specific gravity & 0.91 & 0.93 & 0.93 & 0.92 \\
\hline
\end{tabular}


GC-MS analyses providing data for quantification of compounds were divided into three classes: gasoline $\left(\mathrm{C}_{4}-\mathrm{C}_{9}\right)$, kerosene $\left(\mathrm{C}_{10}-\mathrm{C}_{15}\right)$, and diesel $\left(\mathrm{C}_{16}-\mathrm{C}_{24}\right)$ based on the percentage of peak area on GC chromatogram. The weight of the gas products was estimated by weight of RSO subtracted by weight of the residual oil, the liquid product, and the coke formed. Solid product obtained after decanting the liquid products was assumed as coke.

The constants $(k)$ are reaction rate constants of products such as: diesel, kerosene, gasoline, gas, and coke. They are temperaturedependent, calculated in accordance with the Arrhenius expression. Determination of the activation energy was performed using the Arrhenius Equation (Equation (3)) and calculating the activation energies $(E)$ and frequency factor for $(A)$ each reaction by plotting logarithmic reaction rate constant against reciprocal temperature. The activation energy was obtained from the slope of the plot, whereas the intercept was used to determine the preexponential factor.

$$
k=A \exp \left(-\frac{E}{R T}\right)
$$

\subsection{Prediction of the 6-lump Kinetic Model}

To validate the kinetic modeling, scatter diagram predicted and other new experimental data was utilized. $R$-squared $\left(R^{2}\right)$ is a statistical measure of how close the experimental data are to the fitted regression line. root-mean-square error (RMSE) is a frequently used measure of the differences between values predicted by a model or an estimator and the values actually observed. The sum of squares of error (SSE) and the total of sum of squares (SST) were used to define the $R^{2}$ and $R M S E$ as equation (47 ), where $Y_{\text {exp }}$ is yield from experimental data and $Y_{\text {model }}$ is yield from model.

$$
\begin{aligned}
& R^{2}=1-\frac{S S E}{S S T} \\
& R M S E=\sqrt{S S E} \\
& S S E=\sum_{i=1}^{n}\left(Y_{\exp , i}-Y_{\text {model }, i i}\right)^{2} \\
& S S T=\sum_{i=1}^{n}\left(Y_{\exp , i}-\bar{Y}_{\exp }\right)^{2}
\end{aligned}
$$

\section{Results and Discussion}

Oil product from the cracking of RSO by sulfuric acid was mainly composed of n-paraffin, branched-chain and cyclic-chain paraffin, and aromatics (derivatives of benzene). Some products of rubber seed oils including gas, gasoline, kerosene, diesel, and coke.

\subsection{Lumped Catalytic Cracking Reaction Model}

The reaction network employed for the kinetic modeling of the liquid fuel of RSO is presented in scheme of Figure 2. The lumps of cracking products were calculated based on the weight fraction.

This model requires 6 parameters to facilitate the data processing obtained from experiments. Using this model some simultaneously reaction occurrences in a set of experiments based on a 6-lump derivative model can be shown [6]. This model consists of a series of liquid products divided into three series, namely gasoline, kerosene, and diesel fraction. In each lump, it is assumed that the larger hydrocarbons will be cut down into smaller hydrocarbons. The parameter of kinetic reaction of 6 lump model was estimated in Equation (14-21).

$$
\begin{aligned}
& R_{\text {diesel }}=k_{11} C_{\text {oil }}-k_{5} C_{\text {diesel }} \\
& R_{\text {herosene }}=k_{12} C_{\text {oil }}+k_{51} C_{\text {diesel }}-k_{6} C_{\text {heyosene }} \\
& R_{\text {gasoline }}=k_{13} C_{\text {oil }}+k_{52} C_{\text {diesel }}+ \\
& k_{61} C_{\text {kerosene }}-k_{7} C_{\text {gasoline }} \\
& R_{\text {gas }}=k_{21} C_{\text {oil }}+k_{51} \mathrm{C}_{\text {diesel }}+k_{62} C_{\text {herosens }}+ \\
& k_{71} C_{\text {gasoline }}-k_{4} C_{\text {gas }} \\
& R_{\text {coke }}=k_{22} C_{\text {oil }}+k_{54} \mathrm{C}_{\text {diesel }}+k_{6 \mathrm{~B}} C_{\text {herosene }}+ \\
& k_{72} C_{\text {gasoline }}+k_{4} C_{\text {gas }} \\
& k_{5}=k_{51}+k_{51}+k_{53}+k_{54} \\
& k_{6}=k_{61}+k_{62}+k_{6 \mathrm{~A}} \\
& k_{7}=k_{71}+k_{72}
\end{aligned}
$$

where $R_{i}$ reaction rate of species $\mathrm{i}$; $k_{i}$ is reaction rate constant of species $\mathrm{i} ; k_{i j}$ is reaction rate constant of species $i$ into species $j$; and $C_{i}$ is concentration of species $i$. 


\subsection{Effect of Temperature}

In some cases, RSO was converted to gas phase, liquid phase, and coke at various temperatures and various times of catalytic cracking reaction at concentrations of catalyst 0.5 wt.\%. Effect of reaction temperatures on the conversion of RSO with sulfuric acid catalyst was examined. The effect of temperature on the yield was studied by varying the temperature of $350-450{ }^{\circ} \mathrm{C}$. Figure 3 shows the yield of product catalytic cracking with reaction time for 90 minutes by varying temperature. It has been observed that the yield of liquid and gaseous product is highly influenced by the increase in temperature. The optimum yield of cracking

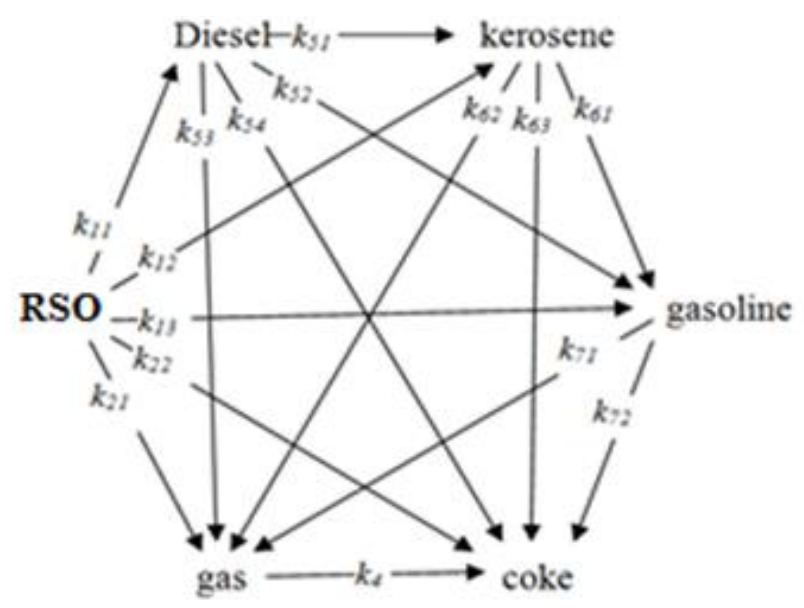

Figure 2. Model 6-lump catalytic cracking of rubber seed oils

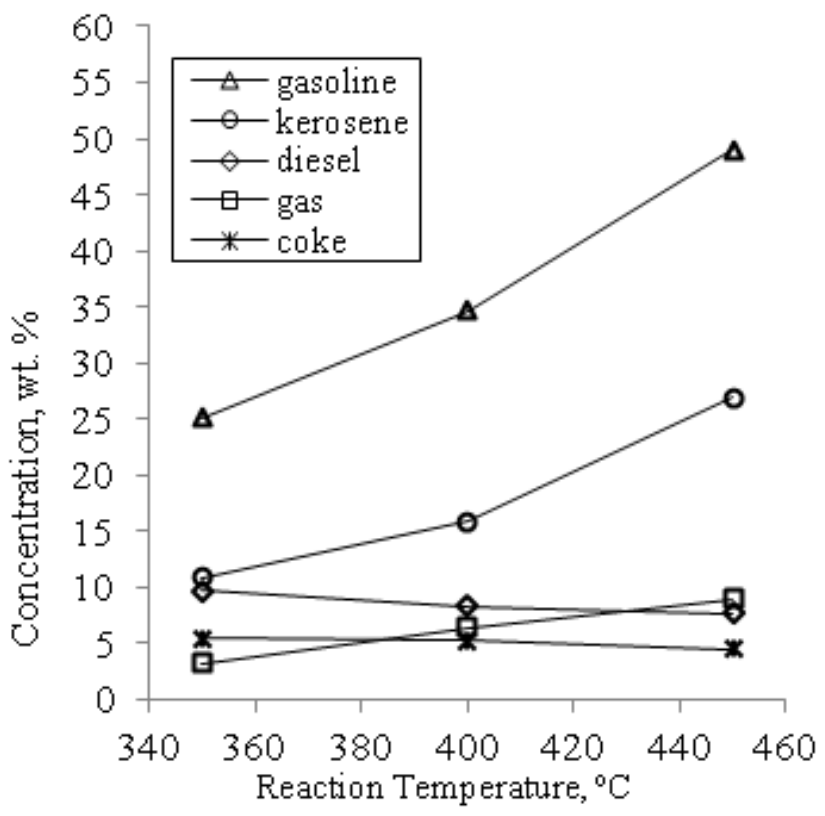

Figure 3. Variation temperature of reaction for 90 minutes using 0.5 wt. $\%$ catalyst reaction of RSO to liquid product is $78 \%$ at 450 ${ }^{\circ} \mathrm{C}$ (Table 3) using 0.5 wt.\% sulfuric acid catalyst from total yield product 97 wt.\%. The higher temperature $\left(450{ }^{\circ} \mathrm{C}\right)$ accelerates the thermal decomposition and changes long-chain hydrocarbon molecules into middle/light hydrocarbon molecules by catalytic cracking. In other case, catalytic cracking using palm oil had an optimum yield as well with the same fraction product [6].

The concentration of each cracking reaction product at temperatures of $350-450{ }^{\circ} \mathrm{C}$ increased with increasing temperature. At catalyst concentration of $0.5 \mathrm{wt} . \%$ and reaction time of 30 minutes, the concentration of each reaction product decreased except the gas product. This might be caused by the amount of catalyst added to the reaction conditions which was not sufficient to catalyze the cracking reaction resulting in decrease in the conversion of each product. The gas product increased with increasing temperature due to the increase in free radical formation at elevated temperature as a consequence of the fragmentation reaction without hydrogen due to the high molecular energy levels of the reactants. Cracking activity increased, occurred randomly and less controlled so that the generated gas product (light fractions) increased as well.

The results of catalytic cracking from RSO with sulfuric acid are the gasoline and kerosene fractions which increased with increasing reaction time. The coke formation seemed have a close relationship with the gasoline fraction, but not with the kerosene fraction. The secondary/continued cracking reactions occurred. It was observed that the most of the kerosene fraction from diesel fraction cracked. Deviation of reaction kinetics for diesel and gas fraction in fitting method were probably due to both are the products that are kinetically not stable, so that when equilibrium is reached, the fractions are not found in large numbers because of consumed and converted into more dominant products. The dominant products which are stable kinetically and thermodynamically were gasoline fractions with conversion of $48.3 \%$. The similar result was obtained from palm oil with conversion of gasoline of $35 \%$ by using nanocrystalline zeolite[16].

The increase in gas product with increasing temperature may be due to the high cracking activity confirmed to the coke produced. The increasing temperature, the potential for coke became lower. The high cracking activity as a result of the high molecular energy was the dominant factor. The catalyst played fewer roles in declining the potential for coke formation. The 
increasing concentration of the catalyst was not followed by a significant decrease in the amount of coke.

\subsection{Effect of Reaction Time}

Reaction time reflects the interaction between reactants and reactant-catalyst in the reaction system. The reaction time contributed mainly to the liquid yield was increased at 450 ${ }^{\circ} \mathrm{C}$ until $78 \%$. Figure 4 shows the concentrations of RSO, diesel, kerosene, gasoline, gas and coke against the reaction time. Generally, it can be observed that the increase in reaction time resulted in the increasing concentrations of liquid products at catalyst concentration 0.5 wt. $\%$ and reaction temperature $450{ }^{\circ} \mathrm{C}$ with the highest gasoline concentration. This is because the longer the reaction time, the longer the interaction, and the greater probability for reaction. In these conditions, gasoline provided a high selectivity towards liquid product.

Gas product of lighter fractions as the consequences of advanced reaction seems occur. It can be observed from the decrease in the concentration of the gas product of light fractions with increasing reaction time, the possible reaction is the polymerization reaction (incorporation of light fractions to heavier fractions) and isomerization [16]. The effect of reaction time on the product distribution indicates that temperature was also a main factor affecting the conversion of long-chain hydrocarbon to middle-chain hydrocarbon, and continued cracking led to middle hydrocarbon goes to gas fraction [19], low-chain hydrocarbon and coke by increasing the reaction time.

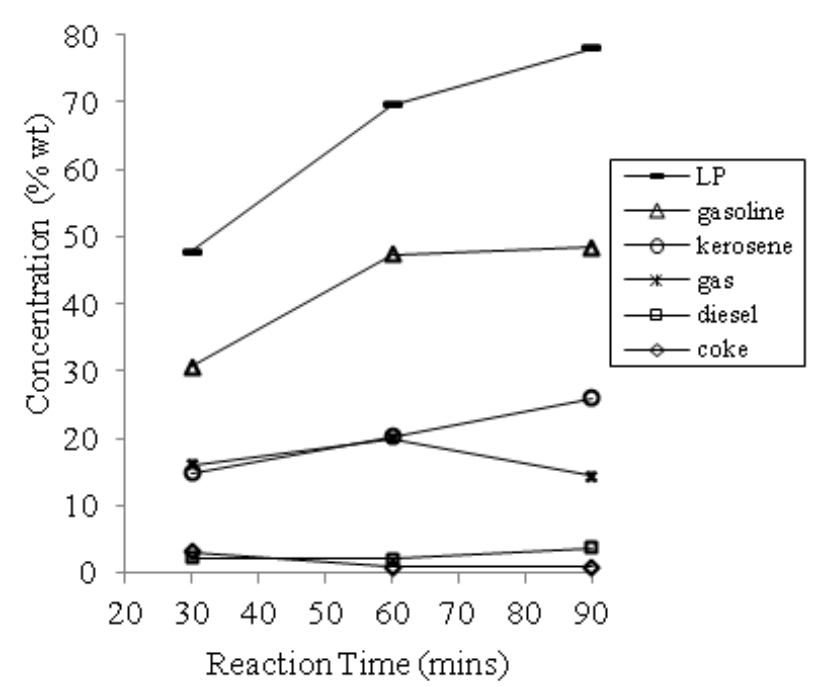

Figure 4. Variation of reaction time of catalytic cracking at $450{ }^{\circ} \mathrm{C}$ using $0.5 \%$ catalyst

\subsection{Effect of Catalyst}

The catalyst can accelerate the rate of reaction that leads to more dominant products in the equilibrium by lowering the activation energy. But the decline in activation energy should be significant enough to accommodate an increase in the rate of reaction, or be accompanied by a very significant increase in frequency factor. If the decrease in activation energy is not significant without a significant increase in frequency factor, the reaction rate will decrease. If the research of liquid fuel development based on natural oil is seriously engaged, the process with high efficiency and does not require a big expense need to be considered.

Figure 5 shows that the yield of the catalytic cracking at temperatures of $450{ }^{\circ} \mathrm{C}$ for variation of catalyst concentrations and reaction times. The catalytic cracking products can be found in the form of liquid fuel, gas, and coke products. The catalytic process for differences in reaction time of 30,60 , and 90 minutes can be seen clearly that the longer the product of liquid fuel, the reaction process of the higher product yields, especially a reaction time of 90 minutes to reach $78 \%$ yield. The use of a catalytic amount ranges from without catalyst up to $2.0 \mathrm{wt} . \%$ of liquid fuel is seen that the optimum concentration of catalyst $1.0 \mathrm{wt} . \%$ that the reaction time of 30 minutes with a yield of $61 \%$. This is in contrast that liquid fuel products with the reaction time of 60 minutes and 90 minutes using $0.5 \mathrm{wt} . \%$ catalyst can achieve the highest yield of $72 \%$ and $78 \%$, respectively. The highest yield of liquid fuels in the catalytic

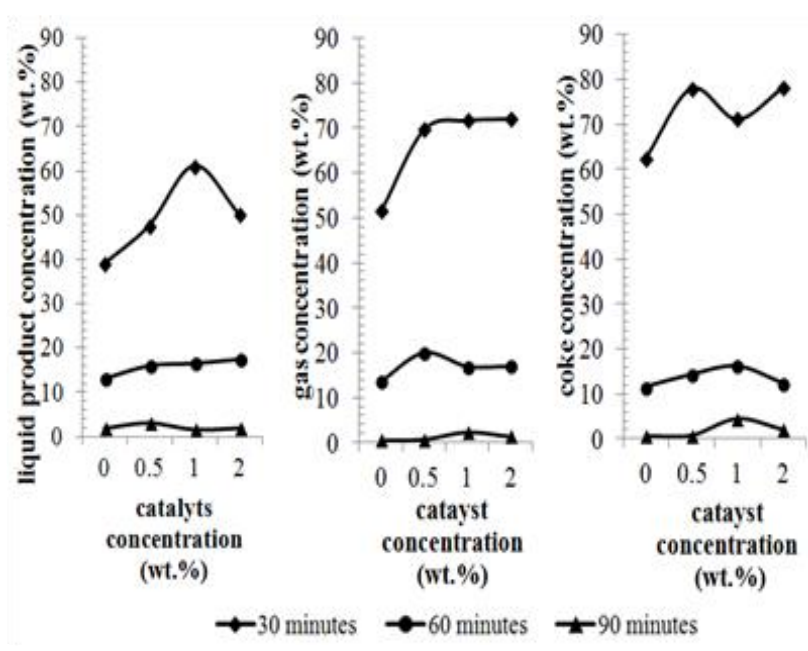

Figure 5. Concentrations of catalytic cracking products at reaction temperature $450{ }^{\circ} \mathrm{C}$ for different catalyst concentrations and reaction times 
Table 3. Gaseous, liquid, and solid product of catalytic cracking of rubber seed oil

\begin{tabular}{|c|c|c|c|c|c|c|c|c|c|}
\hline$T\left({ }^{\circ} \mathrm{C}\right)$ & $t(\min )$ & $\begin{array}{l}\text { Catalyst } \\
\text { (wt.\%) }\end{array}$ & $\begin{array}{c}\mathrm{Xp} \\
\text { (wt.\%) }\end{array}$ & $\begin{array}{c}\mathrm{LP} \\
\text { (wt.\%) }\end{array}$ & $\begin{array}{c}C \text { gasoline } \\
\text { (wt. } \%)\end{array}$ & $\begin{array}{c}C \text { kerosene } \\
\text { (wt. } \%)\end{array}$ & $\begin{array}{c}C \text { diesel } \\
\text { (wt. } \% \text { ) }\end{array}$ & $\begin{array}{l}C \text { gas } \\
\text { (wt. } \% \text { ) }\end{array}$ & $\begin{array}{l}C \text { coke } \\
\text { (wt. } \%)\end{array}$ \\
\hline 350 & 30 & 0.0 & 11.6 & 5.3 & 3.2 & 1.5 & 0.5 & 0.4 & 0.5 \\
\hline 350 & 30 & 0.5 & 14.8 & 11.9 & 7.3 & 3.9 & 0.7 & 1.1 & 1.8 \\
\hline 350 & 30 & 1.0 & 45.8 & 37.4 & 19.8 & 8.2 & 9.4 & 2.9 & 2.8 \\
\hline 350 & 30 & 2.0 & 34.6 & 26.6 & 9.4 & 10.5 & 6.6 & 2.5 & 5.3 \\
\hline 350 & 60 & 0.0 & 17.9 & 15.4 & 8.3 & 2.8 & 4.3 & 0.6 & 1.9 \\
\hline 350 & 60 & 0.5 & 35.7 & 24.7 & 13.6 & 4.0 & 7.1 & 1.6 & 2.2 \\
\hline 350 & 60 & 1.0 & 51.0 & 43.1 & 22.9 & 9.5 & 10.7 & 5.6 & 4.6 \\
\hline 350 & 60 & 2.0 & 67.1 & 53.6 & 22.3 & 9.5 & 21.8 & 2.0 & 5.9 \\
\hline 350 & 90 & 0.0 & 34.4 & 30.4 & 20.4 & 8.4 & 1.5 & 1.5 & 2.5 \\
\hline 350 & 90 & 0.5 & 65.8 & 52.1 & 35.0 & 13.9 & 3.2 & 2.9 & 3.7 \\
\hline 350 & 90 & 1.0 & 56.7 & 46.7 & 25.9 & 10.8 & 10.0 & 3.2 & 5.4 \\
\hline 350 & 90 & 2.0 & 74.7 & 53.5 & 29.4 & 17.4 & 6.7 & 6.2 & 7.7 \\
\hline 400 & 30 & 0.0 & 68.0 & 55.2 & 30.5 & 14.5 & 3.5 & 4.6 & 2.0 \\
\hline 400 & 30 & 0.5 & 82.7 & 67.7 & 40.1 & 20.8 & 6.8 & 6.8 & 5.1 \\
\hline 400 & 30 & 1.0 & 65.8 & 53.2 & 31.2 & 13.0 & 9.0 & 9.0 & 2.1 \\
\hline 400 & 30 & 2.0 & 58.8 & 45.6 & 25.6 & 13.9 & 6.1 & 6.9 & 6.8 \\
\hline 400 & 60 & 0.0 & 46.5 & 39.5 & 24.9 & 10.6 & 4.0 & 5.9 & 1.0 \\
\hline 400 & 60 & 0.5 & 65.7 & 52.0 & 31.5 & 13.0 & 7.4 & 7.6 & 2.9 \\
\hline 400 & 60 & 1.0 & 69.0 & 60.1 & 35.2 & 15.1 & 9.7 & 8.5 & 4.2 \\
\hline 400 & 60 & 2.0 & 74.0 & 58.6 & 33.7 & 16.3 & 8.7 & 8.1 & 4.0 \\
\hline 400 & 90 & 0.0 & 49.5 & 43.6 & 27.4 & 14.1 & 2.1 & 4.3 & 1.6 \\
\hline 400 & 90 & 0.5 & 78.7 & 59.4 & 35.7 & 18.3 & 5.4 & 7.9 & 2.9 \\
\hline 400 & 90 & 1.0 & 78.0 & 58.7 & 34.0 & 15.8 & 8.9 & 6.4 & 5.2 \\
\hline 400 & 90 & 2.0 & 82.9 & 67.3 & 37.8 & 22.3 & 7.2 & 6.9 & 4.8 \\
\hline 450 & 30 & 0.0 & 54.1 & 39.2 & 24.5 & 12.4 & 2.2 & 13.0 & 1.8 \\
\hline 450 & 30 & 0.5 & 71.7 & 47.7 & 30.6 & 14.8 & 2.2 & 16.0 & 3.0 \\
\hline 450 & 30 & 1.0 & 89.1 & 61.1 & 42.3 & 17.2 & 1.7 & 16.6 & 1.5 \\
\hline 450 & 30 & 2.0 & 77.3 & 50.2 & 33.7 & 14.6 & 1.9 & 17.5 & 1.9 \\
\hline 450 & 60 & 0.0 & 65.7 & 51.5 & 34.9 & 16.0 & 0.6 & 13.6 & 0.6 \\
\hline 450 & 60 & 0.5 & 97.0 & 69.6 & 46.4 & 20.3 & 2.0 & 19.9 & 0.8 \\
\hline 450 & 60 & 1.0 & 91.7 & 71.6 & 44.4 & 21.4 & 5.8 & 16.9 & 2.4 \\
\hline 450 & 60 & 2.0 & 94.7 & 72.0 & 44.6 & 23.5 & 3.8 & 16.9 & 1.4 \\
\hline 450 & 90 & 0.0 & 74.6 & 62.4 & 39.5 & 20.4 & 2.4 & 11.5 & 0.7 \\
\hline 450 & 90 & 0.5 & 96.6 & 78.0 & 48.3 & 25.9 & 3.7 & 14.4 & 0.8 \\
\hline 450 & 90 & 1.0 & 97.9 & 71.2 & 43.8 & 22.7 & 4.7 & 16.3 & 4.5 \\
\hline 450 & 90 & 2.0 & 97.9 & 78.0 & 45.3 & 24.6 & 8.3 & 12.3 & 2.1 \\
\hline
\end{tabular}

$T=$ temperature, $t=$ time, $C=$ concentration 
cracking reaction temperature at $450{ }^{\circ} \mathrm{C}$ for 90 minutes using a catalyst of $0.5 \mathrm{wt} . \%$.

Coke formation rate is a measure of the success of the process of production of liquid fuels. In Figure 3 as well, it can be shown that the coke produced were very low (0.8 wt.\%) although with increasing catalyst concentration. At $450{ }^{\circ} \mathrm{C}$ and with a fairly low concentration of catalyst of $0.5 \%$, coke produced reached its lowest point with a reaction time of 90 minutes. In these conditions gasoline fuel fractions also was produced at highest level. Thus, these conditions provide a high selectivity towards gasoline fraction. Effect of usage of catalyst is shown in Figure 6. Gasoline, a dominant product of liquid fuel has the same behavior with liquid fuels. The concentration of gasoline clearly higher for reaction time of 90 minutes than 60 minutes happened at reaction temperature of $450{ }^{\circ} \mathrm{C}$. The use of catalysts 0.5 wt.\% shows an increase of yield product of 20 $25 \%$ than reaction without catalyst. However, the use of 1.0 wt.\% catalyst on catalytic cracking for 90 minutes shows a decrease yield after peak of yield on $0.5 \mathrm{wt} . \%$ catalyst usage.

Some fraction of liquid fuel produced, gasoline fraction always provided the greatest conversion compared to other fractions such as diesel, and kerosene products. In general it can notice that the concentration of gasoline produced as selective product is a function of temperature, catalyst concentration, and reaction time. However, for a reaction time of 90 minutes and a catalyst concentration of 0.5 wt.\%, the trend of gasoline fraction increased with increasing temperature and time is the case. It was due to the limited amount of catalyst in the reaction system was not supported with adequate contact time between reactants.

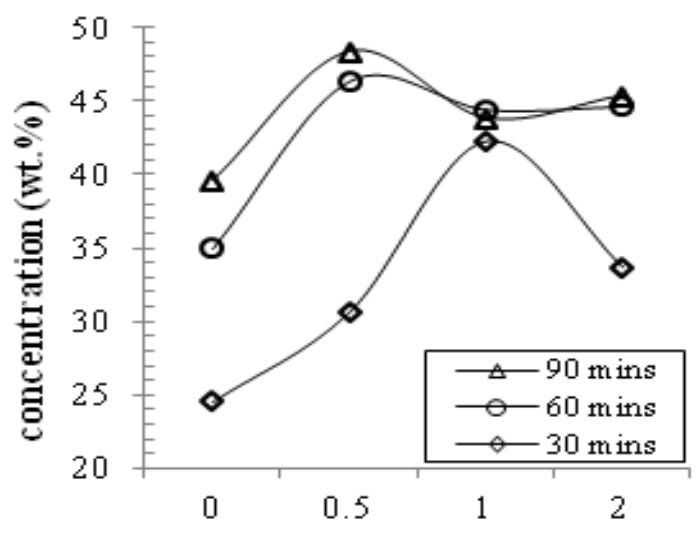

Catalyst concentration (wt.\%)

Figure 6. Gasoline concentration at reaction temperature of $450{ }^{\circ} \mathrm{C}$

\subsection{Kinetics Parameter Estimation}

The reaction rate constants calculated by assuming that each of the single reaction is following the pseudo-first order kinetics. This paper presents the kinetic study of catalytic cracking of RSO catalyzed by homogeneous acid catalyst including the kinetic parameters for each of fuel products as well as activation energy for the reactions undergone. A better understanding about the mechanism of catalytic cracking of RSO will be reported separately.

Kinetic parameters are firstly estimated to detect the fitting capability of lumping models. The reaction rate constants $(k)$ were estimated by solving the system of differential equations (9-21) from model. It was determined by quasifitting method using $f_{\min }$ search program. The model equation is used to predict the yield of products. It is important to include the temperature effect on the kinetic parameters using the Arrhenius law. The $k$ value each product is shown rate formation product. The formation of gasoline, kerosene, and gas is getting higher, while the formation of the diesel and coke decreases for long reaction times and high reaction temperatures. As seen in the Table 5, the

Tabel 4. Reaction rate constant of the 6-lump model

\begin{tabular}{|c|c|c|c|c|}
\hline \multirow{2}{*}{ Reaction } & \multirow{2}{*}{$\begin{array}{l}\text { Para- } \\
\text { meter }\end{array}$} & \multicolumn{3}{|c|}{$\begin{array}{l}\text { Reaction Rate Constant } \\
\qquad\left(\min ^{-1}\right)\end{array}$} \\
\hline & & $350{ }^{\circ} \mathrm{C}$ & $400{ }^{\circ} \mathrm{C}$ & $450^{\circ} \mathrm{C}$ \\
\hline oil $\rightarrow$ diesel & $k_{11}$ & 0.190 & 0.289 & 1.254 \\
\hline oil $\rightarrow$ kerosene & $k_{12}$ & 0.074 & 0.110 & 0.634 \\
\hline oil $\rightarrow$ gasoline & $k_{13}$ & 0.098 & 0.115 & 0.956 \\
\hline $\begin{array}{l}\text { diesel } \rightarrow \text { kero- } \\
\text { sene }\end{array}$ & $k_{51}$ & 0.310 & 0.621 & 1.345 \\
\hline $\begin{array}{l}\text { diesel } \rightarrow \text { gaso- } \\
\text { line }\end{array}$ & $k_{52}$ & 0.026 & 0.081 & 0.143 \\
\hline diesel $\rightarrow$ gas & $k_{53}$ & 0.110 & 0.523 & 0.890 \\
\hline diesel $\rightarrow$ coke & $k_{54}$ & 0.039 & 0.082 & 0.385 \\
\hline $\begin{array}{l}\text { kerosene } \rightarrow \\
\text { gasoline }\end{array}$ & $k_{61}$ & - & - & - \\
\hline $\begin{array}{l}\text { kerosene } \rightarrow \\
\text { gas }\end{array}$ & $k_{62}$ & - & - & - \\
\hline $\begin{array}{l}\text { kerosene } \rightarrow \\
\text { coke }\end{array}$ & $k_{63}$ & - & - & - \\
\hline gasoline $\rightarrow$ gas & $k_{71}$ & - & - & - \\
\hline $\begin{array}{l}\text { gasoline } \rightarrow \\
\text { coke }\end{array}$ & $k_{72}$ & 0.0046 & 0.0110 & 0.2100 \\
\hline
\end{tabular}


values of $k$ gasoline are much higher than the other product. Therefore, the gasoline is produced more in the catalytic cracking than kerosene, gas, coke, and, diesel as obtained in the experimental results.

Determination of the activation energy was performed using the Arrhenius Law and calculating the pre-exponential factors and activation energies. Table 5 shows the activation energies and pre-exponential factors calculated for the reaction parameters. The activation energy is associated with the thermodynamic factors that require an adequate energy, while kinetically the measurement of the accuracy of orientation is reflected by the pre-exponential factor.

Over the temperature range, the average values of energy activation were estimated 100 $\mathrm{kJ} / \mathrm{moles}$ for liquid fuels. The activation energy determined in this paper are close to those reported for catalytic cracking of waste lubricating oil and palm oil was $103.68 \mathrm{~kJ} / \mathrm{moles}$ [19] and $132 \mathrm{~kJ} / \mathrm{moles}$ [6]. Shortly, the catalytic cracking of RSO using sulfuric acid as catalyst is preferred thermodynamically due to the lower activation energy.

\subsection{Prediction of Kinetic Model}

In order to validate the kinetic modeling, diagram of predicted and new experimental data was utilized. $R^{2}$ can take any value between 0 and 1 , with a value closer to 1 indicates a good fitness. The obtained results

Table 5. Pre-exponential factors and Activation energies

\begin{tabular}{ccc}
\hline $\begin{array}{c}\text { Para- } \\
\text { meter }\end{array}$ & $\begin{array}{c}\text { Pre-exponential } \\
\text { Factor, } A\end{array}$ & $\begin{array}{c}\text { Activation Energy, } E \\
(\mathrm{~kJ} / \mathrm{mol})\end{array}$ \\
\hline$k_{11}$ & $1.06 \times 10^{5}$ & 69.46 \\
$k_{12}$ & $3.42 \times 10^{5}$ & 80.94 \\
$k_{13}$ & $6.36 \times 10^{5}$ & 82.79 \\
$k_{51}$ & $1.21 \times 10^{4}$ & 54.92 \\
$k_{52}$ & $2.28 \times 10^{3}$ & 58.97 \\
$k_{53}$ & $5.38 \times 10^{5}$ & 79.09 \\
$k_{54}$ & $3.97 \times 10^{5}$ & 84.30 \\
$k_{61}$ & 1 & - \\
$k_{62}$ & 1 & - \\
$k_{63}$ & 1 & - \\
$k_{71}$ & 1 & - \\
$k_{72}$ & $2.09 \times 10^{9}$ & 140.91 \\
\hline
\end{tabular}

demonstrate that kinetic model is in good agreement with experimental data. A significant test indicates that the observed $R^{2}$ is reliable, and is not a spurious result of oddities in the data set. The $R^{2}$ and RMSE of the test for components such as diesel, kerosene and gasoline are reported closer the value of $R^{2}$ to 1 , the better agreement of experimental data and model prediction is implied.

Figure 7 shows predicted yield of variation in diesel, kerosene, and gasoline with reaction temperatures of 350-450, keeping the reaction time of 90 minutes and ratio catalyst/oil at 1 . The yields increased monotonously with increasing temperature, and that of diesel, kerosene and gasoline showed a maximum of 8.9 wt.\%, 26.9 wt.\%, and 49.0 wt\%, respectively. Maximum error as compared to experimental data for products used in the objective function is $9.4 \%$. The model fits reasonably well with the experimental data were indicated to $R^{2}$ and RMSE. The observed $R^{2}$ is reliable with closer value of $R^{2}$ to 1 , while RMSE are 1.001, 0.666, and 0.330 for gasoline, kerosene, and diesel, respectively. These results have better agreement of experimental data and model prediction.

The higher the reaction temperature, decreasing yield of diesel, followed with increasing yield of the kerosene and diesel. The kinetic rate constants showed that gasoline and kerosene fractions did not undergo secondary cracking reactions compared with the diesel fraction. The diesel tends to take part in secondary reactions.

Figure 8 shows the graph of experimental data versus estimated data of yield. The correlation of values between experimental data and

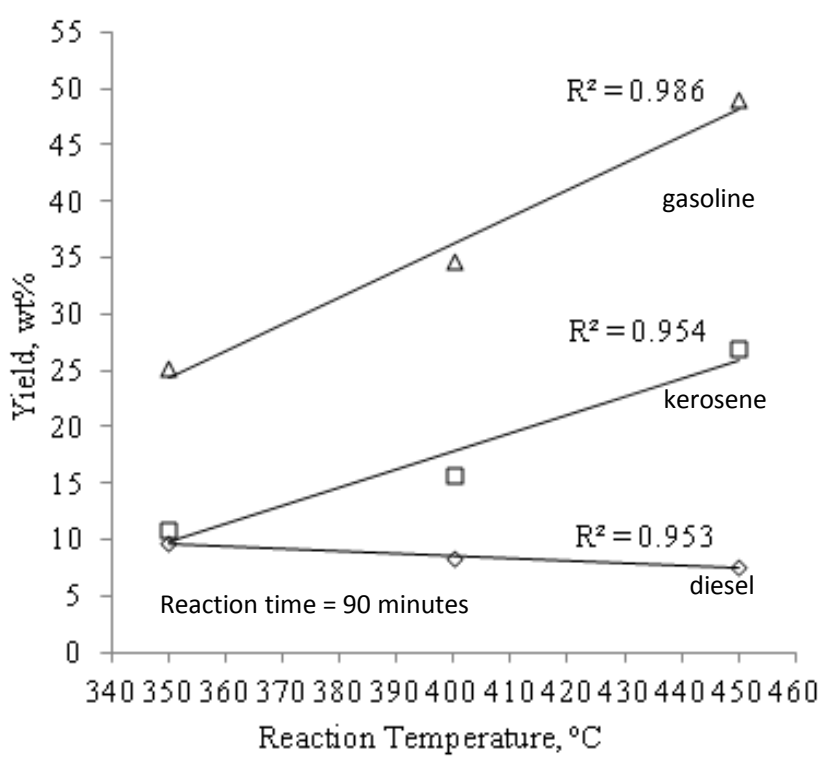

Figure 7. Predicted yields gasoline, kerosene, diesel as a function of reaction temperature 
model were more suitable. Results indicate no meaningful difference in the predicted values though it is obvious that using 6-lumps will provide more details of the catalytic cracking reactions. Maximum error as compared to experimental data for products used in the objective function is $9.4 \%$. In spite of limitation of experimental data for model, the model predictions for product yield describes very well the kinetic phenomena occurring on sulfuric acid catalyst in catalytic cracking of RSO.

\section{Conclusions}

Cracking reaction of RSO catalyzed by sulfuric acid achieved condition at temperature range of 350-450 ${ }^{\circ} \mathrm{C}$ with the concentration of sulfuric acid $0-2$ wt.\% and reactions time of 3090 minutes This reaction was in accordance to the pseudo-order kinetics with the assumption the cracking reaction was the rate limiting step and used 6-lumps models. The advantage of this model was able to predict the main products of liquid fuel. The estimated kinetic parameters, as well as good agreement between model and experimental data were obtained. Concentration expressions of lumping species at the outlet of the reactor have been obtained. Reaction rate constants and model parameters have been estimated with the method and experimental data. Secondary reactions occurred in diesel products compared to gasoline and kerosene. The simulated results have shown that reaction time for 90 minutes, $450{ }^{\circ} \mathrm{C}$ and catalyst concentration $0.5 \mathrm{wt} . \%$ favored the pro-

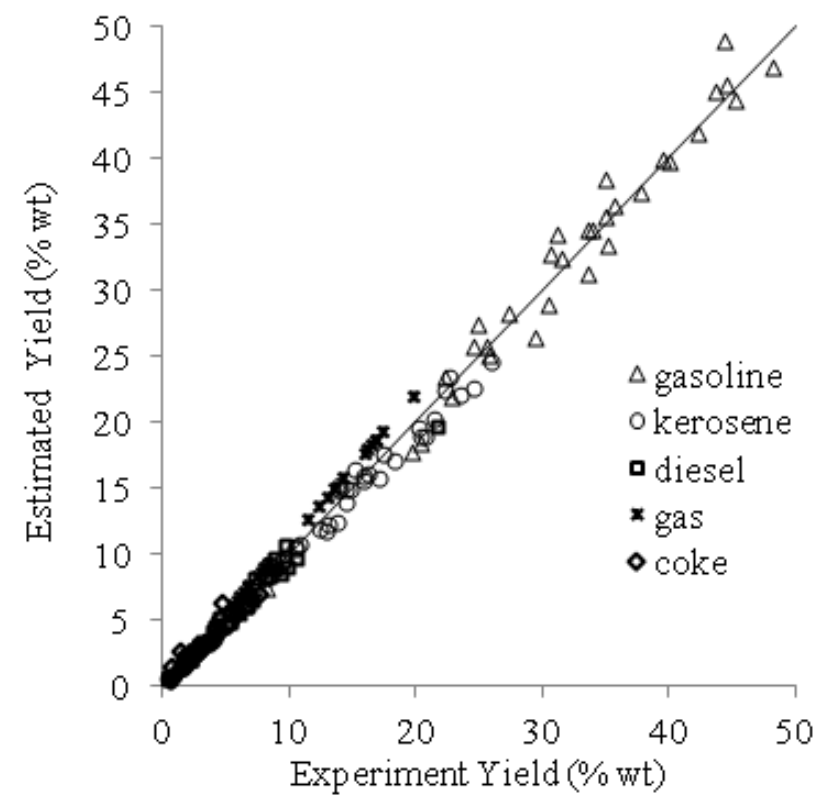

Figure 8. Comparison between experimental and estimated yield duction of liquid fuels with a high selectivity for gasoline fraction and the lowest number of coke.

\section{Acknowledgments}

This work was financially supported by the Directorate General of Higher Education of the Republic of Indonesia for financial support under grant (Fundamental Research No. DIPA023.04.2.189822/2013 and No. 2.14.5/PPK.3.1/ 2013. The authors would like to thank to Universitas Negeri Semarang have supported in this research.

\section{References}

[1] Puhan, S., Vedaraman, N., Rambrahaman, B.V., Nagarajan, G. (2005). Mahua (Madhuca indica), Seed Oil: A Source of Renewable Energy in India. Journal of Scientific and Industrial Research, 64: 890-896.

[2] Demirbas, A. (2007). Progress and Recent Trends in Bio-fuels. Progress in Energy and Combustion Science, 33(1):1-18.

[3] Ramadhas, A.S., Muraleedharan, C., Jayaraj, S. (2005). Performance and Emission Evaluation of A Diesel Engine Fueled with Methyl Esters of Rubber Seed Oil. Renewable Energy, 30: 1789-1800.

[4] Morshed, M., Ferdous, K., Khan, M.R., Mazumder, M.S.I., Islam, M.A., Uddin, M.D.T. (2011). Rubber Seed Oil as A Potential Source for Biodiesel Production in Bangladesh. Fuel, 90: 2981-2986.

[5] Ikhuoria, E. Ui, Aigbodion, A. I., Okieimen F. E. (2004). Enhancing the Quality of Alkyd Resins using Methyl Esters of Rubber Seed Oil. Tropical Journal of Pharmaceutical Research, 3(1): 311-317.

[6] Twaiq, F., Mohamed, A. R., Bhatia, S. (2004). Catalytic Cracking of Palm Oil into Liquid Fuels: Kinetic Study. In Proceedings of The Seventh Asia-Pacific International Symposium on Combustion and Energy Utilization, $1-8$.

[7] Taufiqurrahmi, N., Mohamed, A. R., Bhatia, S. (2011). Nanocrystalline Zeolite Beta and Zeolite $\mathrm{Y}$ as Catalysts in Used Palm Oil Cracking for The Production of Bio-fuel. Journal of Nanoparticle Research, 13: 3177-3189.

[8] Charusiri, W., Yongchareon, W., Vitidsant, T. (2006). Conversion of Used Vegetable Oils to Liquid Fuels and Chemicals Over HZSM-5, Sulphated Zirconia, and Hybrid Catalysts, Korean Journal of Chemical Engineering, 23: 349-355. 
[9] Ramya, G., Sudhakar, R., Amala I.J.J, Ramakrishnan, R., Sivakumar, T., (2012). Liquid Hydrocarbon Fuels from Jatropha Oil through Catalytic Cracking Technology using AlMCM41/ZSM-5 Composite Catalysts. Applied Catalysis A: General 433-434: 170-178.

[10] Li, H., Shen, B., Kabalu, J.C., Nchare, M. (2009). Enhancing The Production of Bio-fuels from Cottonseed Oil by Fixed-Fluidised Bed Catalytic Cracking. Renewable Energy, 34: 1033-1039.

[11] Li, L., Quan, K., Xu, J., Liu, F., Liu, S., Yu, S., Xie, C., Zhang, B., Ge, X. (2014). Liquid Hydrocarbon Fuels from Catalytic Cracking of Rubber Seed oil using USY as Catalyst. Fuel, 123: 189-193.

[12] Cole-Hamilton, D.J. (2003). Homogeneous Catalysis--New Approaches to Catalyst Separation, Recovery, and Recycling. Science, 14(299): 1702-1706.

[13] Sedighi, M., Keyvanloo, K., Towfighi, J. (2004). Kinetic Study of Steam Catalytic Cracking of Naphtha on A Fe/ZSM-5 Catalyst. Energy \& Fuel, 18: 1555-1561.

[14] Leng, Y.T., Mohamed, A.R, Bhatia, S. (1999). Catalytic Conversion of Palm Oil to Fuels and Chemicals. The Canadian Journal of Chemical Engineering, 77: 156-162.
[15] Ooi, Y.S., Yakaria, R., Mohamed, A.R., Bhatia, S. (2004). Catalytic Conversion of Palm Oil-based Fatty Acid Mixture of Liquid Fuel, Biomass and Energy, 27: 477-484.

[16] Ancheyta-JuaÂrez, J., LoÂpez-Isunza, F., Aguilar-RodrõÂguez, E.. (1999). 5-Lump kinetic model for gas oil catalytic cracking. Applied Catalysis A: General, 177: 227-235.

[17] Kittigowittana, K., Wongsakul, S., Krisdaphong, P., Jimtaisong, A, Saewan, N. (2013). Fatty Acid Composition and Biological Activities of Seed Oil from Rubber (Hevea brasiliensis) Cultivar RRIM 600. International Journal of Applied Research in Natural Products. 6(2): 1-7.

[18] de Klerk, A. (2007). Thermal Cracking of Fischer-Tropsch Waxes. Industrial \& Engineering Chemical Research, 46: 5516-5521.

[19] Permsubscul, A., Vitidsant, T., Damronglerd, S. (2007). Catalytic Cracking Reaction of Used Lubricating Oil to Liquid Fuels Catalyzed by Sulfated Zirconia. Korean Journal of Chemical Engineering, 24(1): 37-43. 